\title{
Stroke Types in Rural and Urban Northern Portugal: Incidence and 7-Year Survival in a Community-Based Study
}

\author{
Manuel Correia a, ${ }^{a}$ Rui Magalhães ${ }^{b}$ Mário Rui Silva ${ }^{c}$ Ilda Matos ${ }^{d}$ \\ Maria Carolina Silvab \\ aServiço de Neurologia, Hospital de Santo António - Centro Hospitalar do Porto, and \\ bUNIFAI, Instituto de Ciências Biomédicas de Abel Salazar (ICBAS), Universidade do Porto, \\ Porto, ' Serviço de Neurologia, Hospital de S. Pedro - Centro Hospitalar de Trás-os-Montes \\ e Alto Douro, Vila Real, and d Serviço de Neurologia, Hospital de Mirandela - Centro \\ Hospitalar do Nordeste, Mirandela, Portugal
}

Key Words

Stroke · Incidence · Survival · Prognosis · Rural/urban Portugal

\section{Abstract}

Background/Aim: Differences in stroke incidence and mortality between regions could stem from differences in the incidence of particular stroke types and long-term prognosis. The aim of this study was to investigate whether different risk profiles and stroke types underlie the difference in stroke incidence and patient long-term survival in rural and urban populations. Methods: All suspected first-ever-in-a-lifetime strokes occurring between October 1998 and September 2000 in 37,290 residents of rural municipalities and in 86,023 individuals living in the city of Porto were entered into a population-based registry. Standard definitions of stroke types and overlapping comprehensive sources of information were used for patient identification. Patients were examined by neurologists at 3 months, 1 year and 7 years after the index event. Results: From a total of 688 patients included (226 in rural and 462 in urban areas), $76.2 \%$ had an ischaemic stroke (IS; 75.3 vs. $77.9 \%), 16.1 \%$ a primary intracerebral haemorrhage ( $\mathrm{PICH} ; 16.3$ vs. $14.6 \%)$ and $3.3 \%$ a subarachnoid haemorrhage $(\mathrm{SAH} ; 2.7$ vs. $3.7 \%)$; in $4.4 \%$ (4.9 vs. $4.1 \%)$, the stroke type could not be determined. The annual incidence rate per 1,000 was 2.13 (95\% CI, 1.95-2.31), 0.45 (95\% CI, 0.37-0.53), 0.09 (95\% CI, 0.06-0.14) and 0.12 (95\% CI, $0.08-0.17)$, respectively. The age-specific rural/urban incidence rate ratios for IS in the youngest group (<55 years) was 0.27 ( $95 \% \mathrm{CI}, 0.11-0.69$ ), increasing to 1.47 (95\% CI, 1.07-2.01) for those aged $65-74$ years and to 1.87 (95\% CI, 1.39-2.52) for those between 75 and 84 years. Rural compared to urban patients with an IS were predominantly men, had a prevalence ratio (PR) of 1.28 (95\% CI, 1.05-1.56), were 65 years or older (PR = 1.18; 95\% CI, 1.08-1.30) and had 
Correia et al.: Stroke Types in Rural and Urban Northern Portugal: Incidence and

7-Year Survival in a Community-Based Study

in general a lower prevalence of risk factors. There was no evidence of rural/urban differences in 28-day case fatality for the stroke types, although IS tended to be less fatal among urban patients (10.3 vs. $13.1 \%)$, whereas PICH (33.3 vs. $24.2 \%$ ) and SAH (35.3 vs. $16.7 \%$ ) were less fatal among rural patients. Independently of rural/urban residence, predictors of poor survival after the acute phase (28 days) were age $>65$ years ( $\mathrm{HR}=3.57 ; 95 \% \mathrm{CI}, 2.6-4.9)$, diabetes $(\mathrm{HR}=1.5 ; 95 \% \mathrm{CI}, 1.2-1.9)$, ischaemic heart disease $(\mathrm{HR}=1.8 ; 95 \% \mathrm{CI}, 1.3-2.6)$, atrial fibrillation ( $\mathrm{HR}=1.5 ; 95 \% \mathrm{CI}, 1.1-2.0)$ and smoking habits ( $\mathrm{HR}=1.6 ; 95 \% \mathrm{CI}, 1.1-2.3)$. Conclusions: The age pattern of IS incidence marks the difference between rural and urban populations; the youngest urban and the oldest rural residents were at a higher risk. Although patients from rural areas were older, the relatively lower prevalence of simultaneously occurring risk and prognostic factors among them as well as the similar management of rural and urban patients may justify why rurality is not associated with long-term survival.

(C) 2013 S. Karger AG, Basel

\section{Introduction}

Despite the continuous decrease in mortality rates from stroke in Portugal in the last two decades [1], disparities still remain in standardized rates among rural $(77.1 / 100,000)$ and urban $(71.8 / 100,000)$ areas in northern Portugal [2]. We have shown that this excess mortality in rural areas could be partially explained by a higher incidence of stroke and not by short-term case fatality, i.e., $30.1 \%$ in rural areas compared to $27.9 \%$ in the city of Porto in the first year following the first-ever-in-a-lifetime stroke (FELS) [3]. Rather than being a single pathological entity, stroke is a disease that includes distinct types having different incidence rates, risk profiles, management guidelines and outcomes that may lead to different disease burdens in different regions. Comparing the incidence of different stroke types as well as the risk profiles and long-term survival of patients with these stroke types in rural and urban populations may add important knowledge about their aetiology, prevention and prognosis. In order to accurately assess the incidence of different stroke types, studies investigating stroke incidences must meet ideal criteria [4,5], such as the use of diagnostic brain imaging for the majority (ideally for all) of the patients [6]. In accordance to these criteria, a community-based prospective stroke registry was set up in northern Portugal [3]. The aim of this article is to present data on stroke types regarding incidence, risk profile and long-term survival for understanding the patterns of stroke in rural and urban populations.

\section{Population and Methods}

The ACINrpc was a community-based study of the incidence and outcome of FELS and transient neurological focal symptoms and signs. The overall design of the project has been described in detail elsewhere [3]. In brief, the study population comprised 123,112 individuals registered and identified by a unique health service at five health centres on September 30, 1999 (mid-study period): 37,089 in rural areas and 80,023 in the city of Porto. This population was not significantly different from the corresponding geographic population [3]. Case ascertainment lasted from October 1, 1998, to September 30, 2000, and included both 'hotand cold-pursuit data collection' using a variety of overlapping sources of information.

A study neurologist examined all suspected cases as soon as possible, and a CT was performed after the event. Medical records from hospitals and/or general practitioners (GP) were checked for details of any previous event and vascular risk factors (VRF). The principal investigator reviewed the information of each patient and classified the type of stroke; 


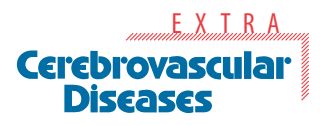

Fig. 1. Ascertainment and inclusion of FELS in northern Portugal and details of the 7-year followup.

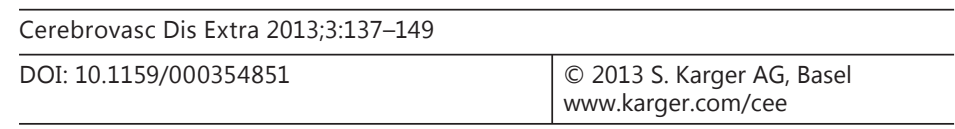

Correia et al.: Stroke Types in Rural and Urban Northern Portugal: Incidence and 7-Year Survival in a Community-Based Study

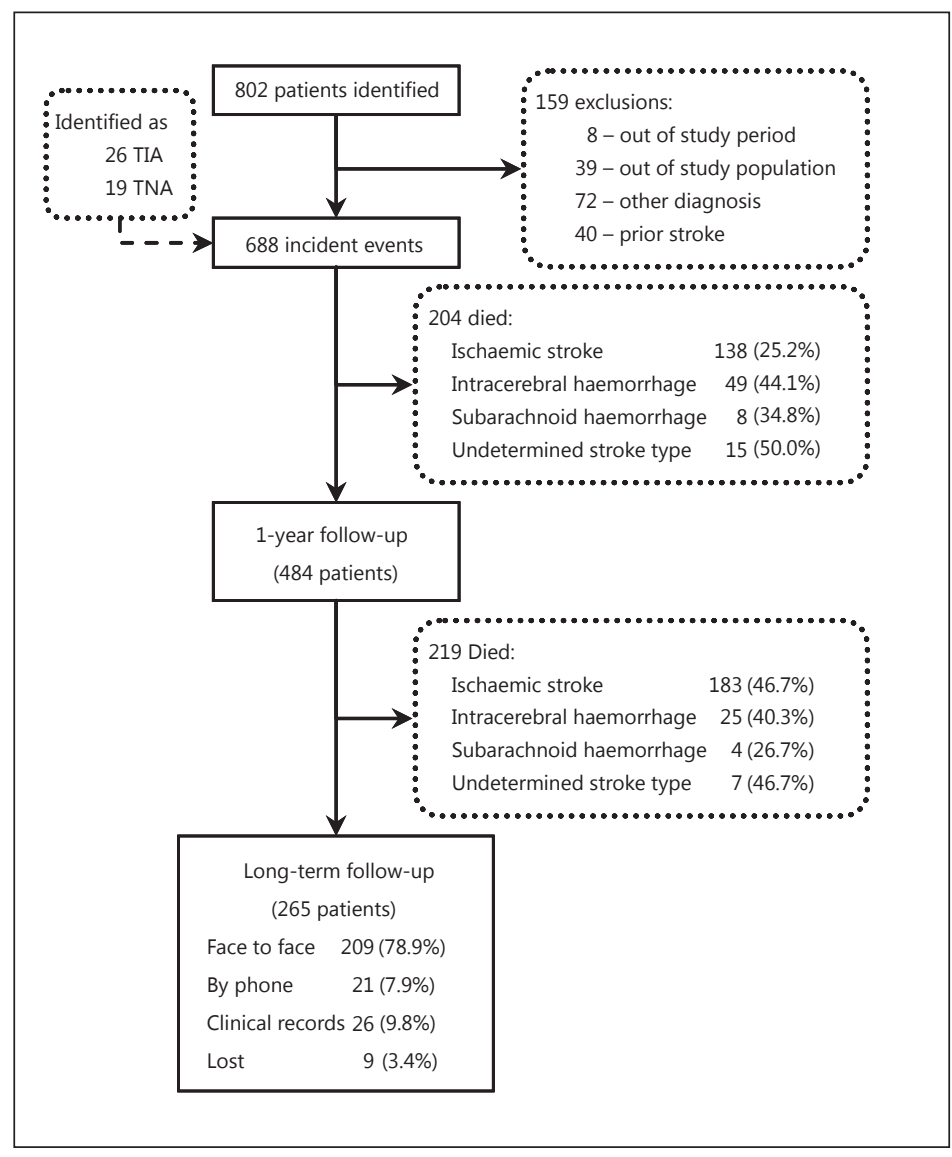

whenever appropriate, the classification was established after consensus between the neurologist who first examined the patient and the principal investigator.

All patients were followed up by neurologists at 3 months, 1 year and 7 years after the index event. The long-term follow-up began in September 2005, and every attempt was made to include all patients alive at the 1-year follow-up (fig. 1). The process began by updating the telephone contacts of the patients using health centre/hospital administrative files and all available information on patient medical records. This was followed by a first contact by phone made 15 days before the end of the 7-year period, and, when this failed, two letters were sent explaining the study purpose and suggesting a date for a consultation. Patients who collaborated but were not willing to complete the consultation were contacted by phone, and for those unable to come to the hospital, home visits were scheduled. For patients known to be deceased based on previous information, a family member/caregiver had to give information about the date and circumstances of death; otherwise, a search was done in the computer files held at the Northern Regional Health Administration. In case of death, information about date and circumstances of death was confirmed by manual inspection of written monthly reports at each health centre since current legislation forbids the use of death certificates for research purposes. This information was linked to existing clinical records for assigning the underlying cause of death, determined by a study neurologist. If no contact or information could be obtained, the patient was considered lost to follow-up.

Stroke was defined according to the World Health Organization [7], and stroke types were classified according to Sudlow and Warlow [5] as ischaemic stroke (IS), primary intra- 
Correia et al.: Stroke Types in Rural and Urban Northern Portugal: Incidence and

7-Year Survival in a Community-Based Study

cerebral haemorrhage (PICH) and subarachnoid haemorrhage (SAH). If no brain CT scan was performed within 30 days and no autopsy, lumbar puncture or angiography (in case of suspected SAH) results were available, stroke was classified as undetermined. For VRF, the following definitions were used: for hypertension, a history of high blood pressure (BP) or an anti-hypertensive treatment or systolic BP >160 mm Hg and/or diastolic BP >95 mm Hg on at least two different measures; for diabetes, a previous diagnosis/treatment of diabetes mellitus with oral anti-diabetic/insulin or fasting glycaemia $>126 \mathrm{mg} / \mathrm{dl}$, postprandial glycaemia $\geq 200 \mathrm{mg} / \mathrm{dl}$ and/or a glucose tolerance test with values of glycaemia $\geq 200 \mathrm{mg} / \mathrm{dl}$ at the second hour; for hypercholesterolaemia, a previous diagnosis/treatment of hypercholesterolaemia or a serum total cholesterol level after $12 \mathrm{~h}$ of fasting $\geq 240 \mathrm{mg} / \mathrm{dl}$; and for cardiac disease, a previous diagnosis of angina, myocardial infarction (MI) or atrial fibrillation by EKG confirmation, a previous diagnosis of a transient ischaemic attack (TIA), and smoking, categorized as never smoked, smoked regularly but not in the preceding 12 months (ex-smoker) and current smoker.

The Ethics Committee of the Hospital de Santo António, where the study coordination centre was located, approved the study. Informed consent was obtained from each participant, or from the next of kin when appropriate, before any clinical assessment. Since medical records are part of the National Health Service institutions, for follow-up purposes clinical files were used whenever the patient could not be contacted.

\section{Statistical Analysis}

The distribution of patient characteristics at baseline according to stroke type is described. The crude incidence rates age-standardized to the Portuguese [8] and European populations [9] are reported, and the $95 \%$ confidence intervals (CI) were calculated by the Poisson distribution. The rural/urban ratios of VRF prevalence, stroke incidence and case fatality were calculated based on cross-tabulation and were used to compare rural and urban patients. The Kaplan-Meier estimates for the cumulative risk of death for stroke types over a period of 7 years after the index event were calculated in rural and urban patients. After checking the assumption of proportional hazards with the Schoenfeld's test, the rural/urban hazard ratios (HR) were calculated using a Cox model including the baseline risk profiles. Since this assumption failed when considering the time from the index event until death over the 7-year follow-up, this model was restricted to patients surviving the acute phase (28 days).

\section{Results}

Of the 688 FELS (226 in rural and 462 in urban areas), 76.2\% were IS (75.3 in rural vs. $77.9 \%$ in urban), $16.1 \%$ were PICH (16.3 vs. $14.6 \%), 3.3 \%$ SAH (2.7 vs. $3.7 \%$ ) and $4.4 \%$ of undetermined stroke type (4.9 vs. $4.1 \%$ ). More cases in rural compared to urban areas were ascertained by 'hot-pursuit' and sooner after the event. Nearly $56 \%$ of the patients were admitted to the hospital, with a similar proportion for IS in both rural and urban areas but a lower proportion of PICH in the rural area (69.7 vs. 96.2\%). Overall, a CT scan was performed in $96.9 \%$ of the patients (not done in 12 urban and 9 rural patients) and in $70.3 \%$ within $24 \mathrm{~h}$ following the event.

\section{Vascular Risk Profiles and Incidence}

Although patients were mostly women (58.7\%), men predominated in rural areas (48.2 vs. 37.9\%) either with an IS or PICH; patients from rural areas were older than patients from urban areas, especially those with an IS (table 1). Hypertension was the most prevalent VRF $(60.9 \%)$, whereas a previous TIA was seldom registered (8.6\%). In general, the prevalence of 
Correia et al.: Stroke Types in Rural and Urban Northern Portugal: Incidence and 7-Year Survival in a Community-Based Study

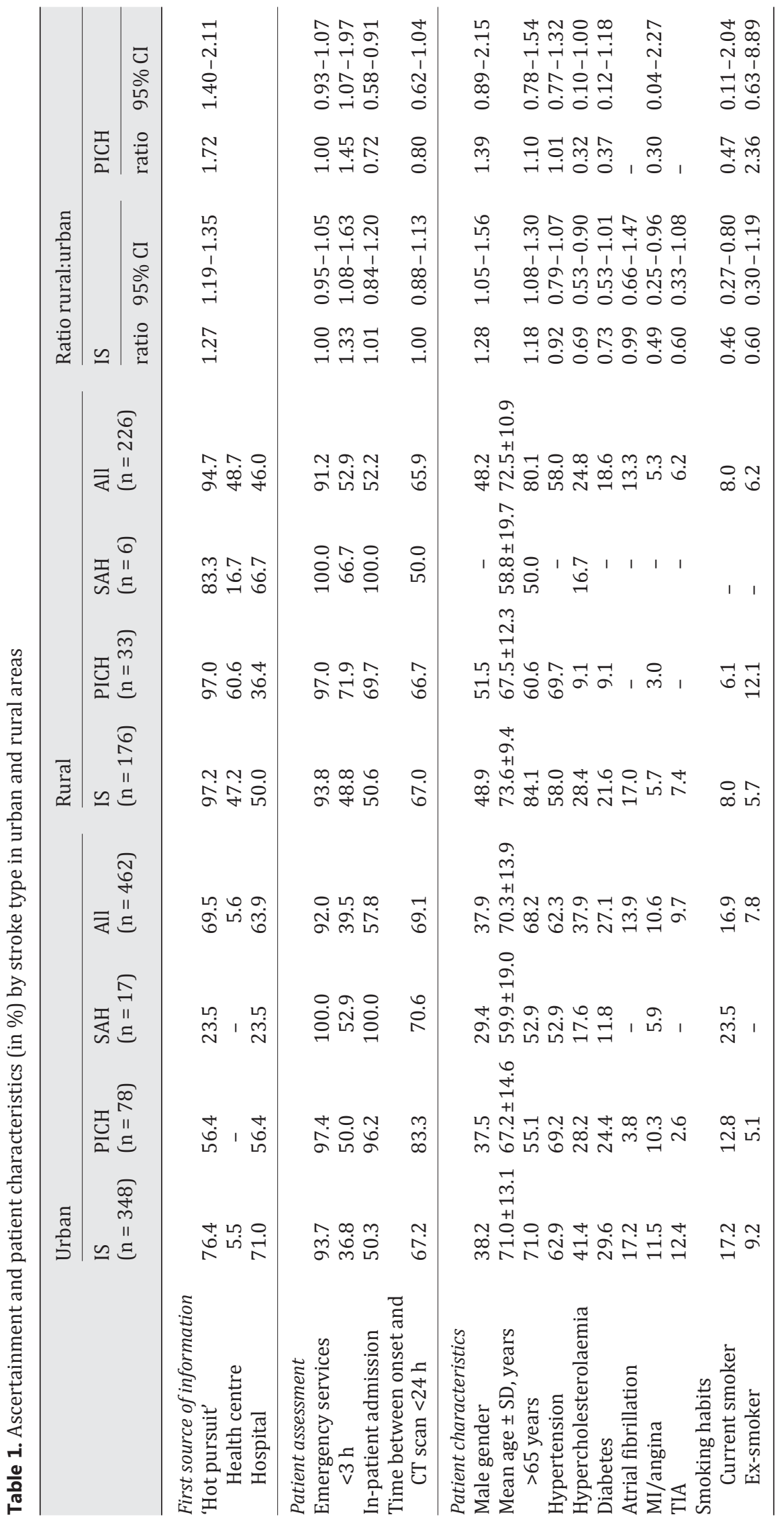




\begin{tabular}{l|l}
\hline Cerebrovasc Dis Extra 2013;3:137-149 \\
\hline DOI: 10.1159/000354851 & $\begin{array}{l}\text { C 2013 S. Karger AG, Basel } \\
\text { www.karger.com/cee }\end{array}$ \\
\hline Correia et al.: Stroke Types in Rural and Urban Northern Portugal: Incidence and
\end{tabular}

Correia et al.: Stroke Types in Rural and Urban Northern Portugal: Incidence and 7-Year Survival in a Community-Based Study

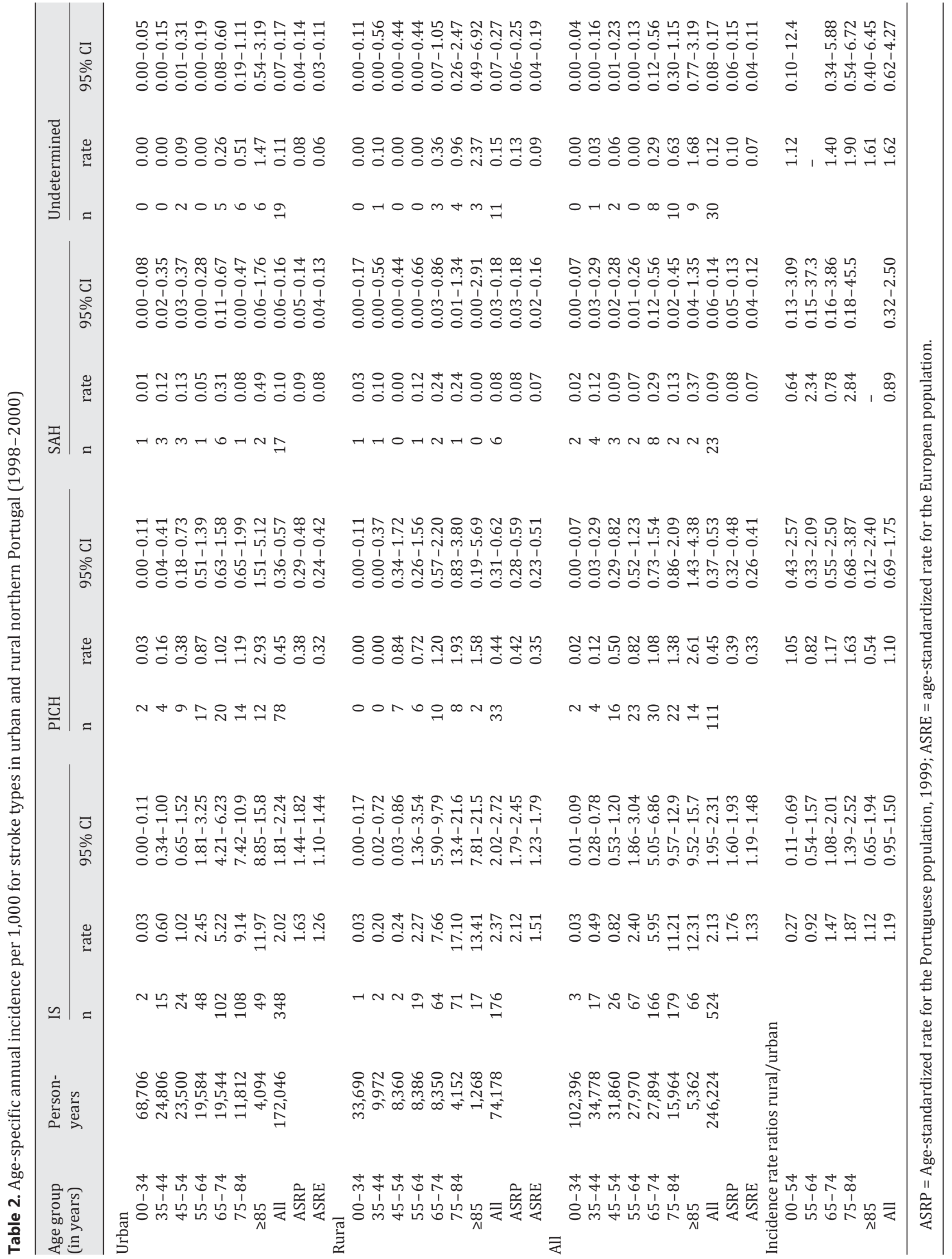


VRF was lower in rural compared to urban patients, namely cardiac disease (IS and ICH), hypercholesterolaemia and smoking habits (IS).

The crude overall annual incidence rate per 1,000 population was 2.13 (95\% CI, 1.952.31) for IS, 0.45 (95\% CI, 0.37-0.53) for PICH, 0.09 (95\% CI, 0.06-0.14) for SAH and 0.12 (95\% CI, 0.08-0.17) for strokes of undetermined type; adjusted for the European population, these rates were 1.33 (95\% CI, 1.19-1.48), 0.33 (95\% CI, 0.25-0.41), 0.07 (95\% CI, 0.04-0.12) and 0.07 (95\% CI, 0.04-0.11), respectively (table 2). The ratio of rates indicates that the incidence of IS in the youngest group ( $<55$ years) was lower in rural compared to urban populations, particularly in men $(0.12 ; 95 \% \mathrm{CI}, 0.02-0.91)$. The opposite trend was found among those aged $65-84$ years $(2.19 ; 95 \% \mathrm{CI}, 1.37-3.49$ in men and $1.65 ; 95 \% \mathrm{CI}, 1.12-2.45$ in women; results not shown). For the remaining stroke types, there was no evidence of differences in the age pattern of incidence rates between the rural and urban environment.

\section{Short- and Long-Term Survival}

Of the 688 FELS patients, 204 (29.7\%) died during the first year; the 7-year follow-up details for the 484 survivors are described in figure 1 . Nine patients were lost after the 1-year follow-up (1.1-2.4 years), mostly because they had changed residence or went abroad (7 IS, $1 \mathrm{PICH}$ and $1 \mathrm{SAH})$. Among the 209 (78.9\%) patients examined by the neurologist, $21(10 \%)$ were visited at their homes. The follow-up time ranged from 7 to 8.6 years.

By day 28, 59 (11.3\%), 34 (30.6\%), 7 (30.4\%) and 11 (36.7\%) patients had died after the first IS, PICH, SAH and undetermined stroke, respectively. There was no evidence of rural/ urban differences in 28-day case fatality for the different stroke types, although IS tended to be less fatal among urban patients (10.3 vs. $13.1 \%$ ), whereas PICH (33.3 vs. $24.2 \%$ ) and SAH (35.3 vs. $16.7 \%$ ) were less fatal among rural patients, corresponding to rural/urban ratios of 1.26 (95\% CI, 0.77-2.06), 0.73 (95\% CI, 0.37-1.44) and 0.47 (95\% CI, 0.07-3.16), respectively. The cumulative risk of death at 7 years followed the same pattern: IS was less fatal in urban patients (57.4 vs. 61.5\%), and PICH (67.4 vs. 64.6\%) or SAH (61.2 vs. 33.3\%) were less fatal in rural patients. The proportional mortality from stroke (first or recurrent stroke) was $74.8 \%(83 / 111)$ at 28 days, $48.0 \%$ (98/204) during the first year and 30.3\% (128/423) at the end of follow-up after 7 years. Figure 2 shows the risk of death at 28 days and by year for ischaemic and haemorrhage stroke (PICH and SAH), indicating a relatively constant yearly risk after 3 years in patients with an IS. Table 3 shows the independent baseline predictors of long-term survival after the acute phase. Besides age, diabetes ( $\mathrm{HR}=1.48$; 95\% CI, 1.151.92), $\mathrm{MI}$ /angina ( $\mathrm{HR}=1.80 ; 95 \% \mathrm{CI}, 1.25-2.58)$, atrial fibrillation ( $\mathrm{HR}=1.47 ; 95 \% \mathrm{CI}, 1.07-$ $2.00)$ and being a current smoker ( $\mathrm{HR}=1.60 ; 95 \% \mathrm{CI}, 1.13-2.28)$ increased the risk of death, whereas hypercholesterolaemia was a protective factor ( $\mathrm{HR}=0.45 ; 95 \% \mathrm{CI}, 0.34-0.59$ ). Stroke type and rural/urban residence were not associated with survival after the acute phase.

\section{Discussion}

This is the first study to present a comprehensive picture of the burden of stroke among rural and urban populations, looking at the incidence of stroke types as well as at vascular risk profiles and long-term survival of patients. A high proportion of patients were ascertained by 'hot-pursuit'; almost all underwent a CT soon after the initial symptoms, thus improving the reliability of the results for the incidence of stroke types [5]. Differences in procedural aspects mostly stem from the organization of the National Health Service; health centre services are more readily available than hospital services for rural populations, and in the city this is mainly a question of choice since there are no barriers of distance. Almost all 
Fig. 2. Kaplan-Meier estimates of the cumulative death risk for all patients (a) and the cumulative death risk in 28-day stroke survivors by stroke type (b). $\mathrm{N}=$ Cumulative number of patients.

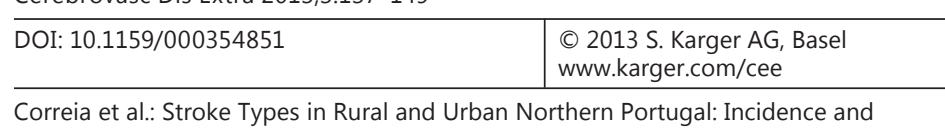

Correia et al.: Stroke Types in Rural and Urban Northern Portugal: Incidence and 7-Year Survival in a Community-Based Study
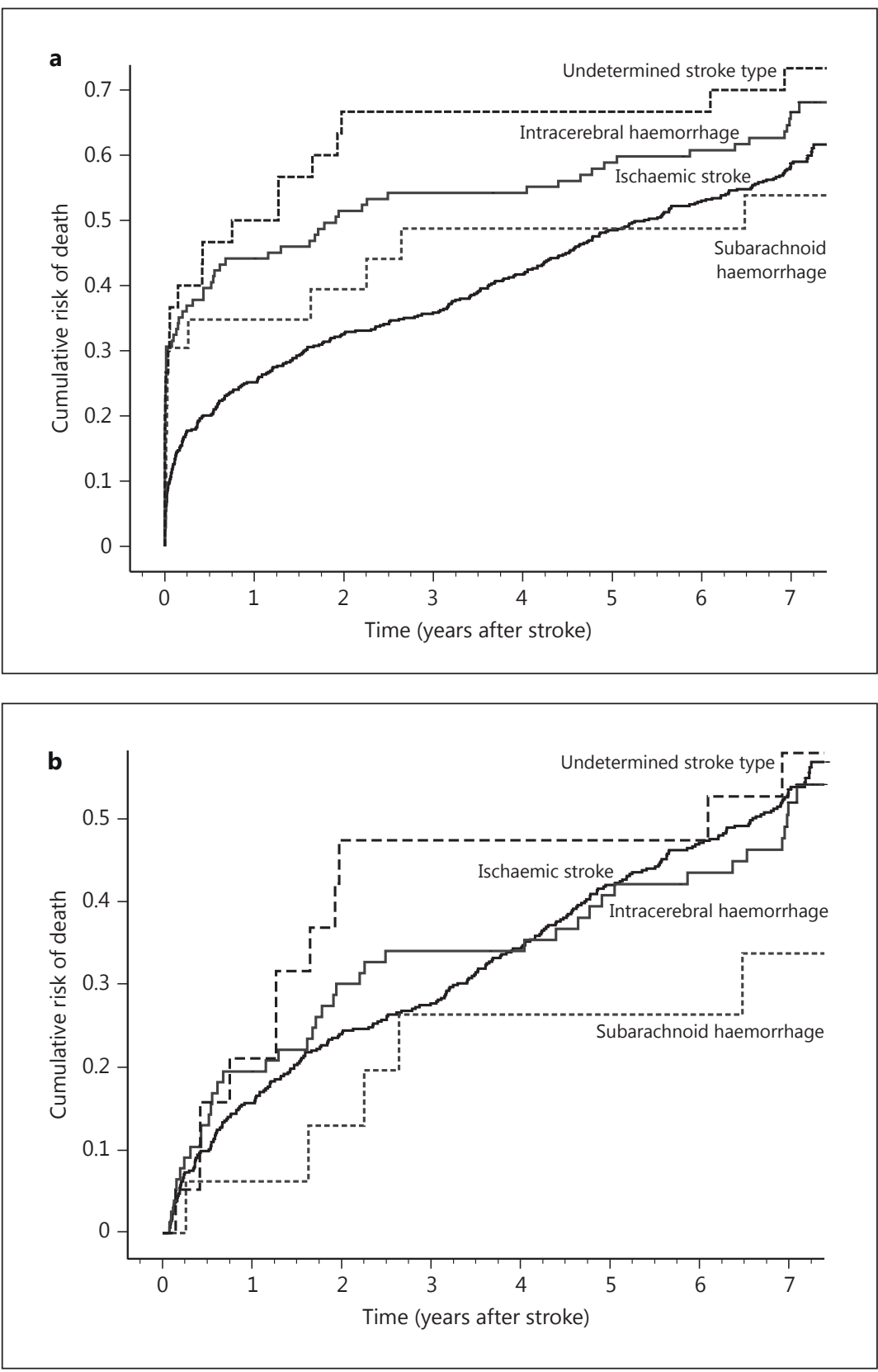


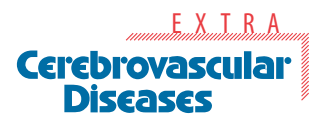

\begin{tabular}{|c|c|}
\hline \multicolumn{2}{|c|}{ Cerebrovasc Dis Extra 2013;3:137-149 } \\
\hline DOI: $10.1159 / 000354851$ & $\begin{array}{l}\text { (C) } 2013 \text { S. Karger AG, Basel } \\
\text { www.karger.com/cee }\end{array}$ \\
\hline
\end{tabular}

Table 3. HR for the association between factors at presentation and death among 28-day survivors

\begin{tabular}{|c|c|c|c|c|}
\hline & \multicolumn{2}{|c|}{ Univariate } & \multicolumn{2}{|c|}{ Multivariate } \\
\hline & HR & $95 \% \mathrm{CI}$ & HR & $95 \% \mathrm{CI}$ \\
\hline \multicolumn{5}{|l|}{ Sociodemographics } \\
\hline Rural versus urban & 1.18 & $0.93-1.49$ & 1.00 & $0.79-1.29$ \\
\hline Men versus women & 1.00 & $0.80-1.26$ & 0.94 & $0.71-1.24$ \\
\hline Age $>65$ versus $\leq 65$ years & 3.58 & $2.62-4.90^{* * *}$ & 3.57 & $2.58-4.95^{* * *}$ \\
\hline \multicolumn{5}{|l|}{ Risk factors (yes vs. no) } \\
\hline Hypertension & 0.81 & $0.64-1.02$ & 0.86 & $0.68-1.09$ \\
\hline Diabetes & 1.21 & $0.94-1.56$ & 1.48 & $1.15-1.92^{* *}$ \\
\hline Atrial fibrillation & 2.01 & $1.49-2.72^{* * *}$ & 1.47 & $1.07-2.00^{*}$ \\
\hline MI/angina & 1.58 & $1.11-2.23^{* *}$ & 1.80 & $1.25-2.58^{* *}$ \\
\hline TIA & 0.92 & $0.61-1.37$ & 0.99 & $0.66-1.47$ \\
\hline Hypercholesterolaemia & 0.46 & $0.36-0.60^{* * *}$ & 0.45 & $0.34-0.59^{* * *}$ \\
\hline \multicolumn{5}{|l|}{ Smoking habits } \\
\hline Ex-smoker & 0.65 & $0.42-1.02$ & 0.80 & $0.49-1.31$ \\
\hline Current smoker & 1.07 & $0.80-1.43$ & 1.60 & $1.13-2.28^{* *}$ \\
\hline \multicolumn{5}{|l|}{ Diagnosis (vs. IS) } \\
\hline $\mathrm{PICH}$ & 0.96 & $0.69-1.34$ & 1.12 & $0.79-1.58$ \\
\hline SAH & 0.52 & $0.21-1.25$ & 0.63 & $0.26-1.75$ \\
\hline Undetermined stroke type & 1.15 & $0.63-2.10$ & 1.28 & $0.69-2.36$ \\
\hline
\end{tabular}

patients (91-92\%) were seen at an 'emergency service'; however, in rural areas it was mostly at the health centre (open $24 \mathrm{~h}$ ) and this is why these patients are more often observed within $3 \mathrm{~h}$ after the stroke. Nevertheless, in case of a PICH, there were fewer hospital admissions of rural compared with urban patients, though they remained in-patients in the health centre. Overall, the health services provided were similar for rural and urban patients, and based on previous studies we know that individuals living in rural areas are more prone to attend the family doctor at the health centre in case of most stroke warning signs than individuals living in urban areas [10].

There was a higher incidence of both IS and PICH in rural than urban areas. Nevertheless, the comparison of standardized rates obscured the differences in the incidence age pattern in the two populations, particularly in IS. On average, the first IS happened almost 3 years earlier in life among the urban population, leading to a higher IS incidence in the youngest group ( $<55$ years), especially in men, whereas for those aged $75-84$ years living in rural areas, the average risk is almost twice as high than in the city. Although patients living in rural areas were older, they had, in general, less traditional VRF than patients living in urban areas, in particular cardiac disease and hypercholesterolaemia in patients with IS. The reduced information and awareness of VRF [10] in rural areas and the consequent lack of monitoring probably led to an under-reporting and/or under-diagnosis, mainly by GPs, since by description of ascertainment, health centre services are 'more accessible' in rural areas. On the other hand, our results go in the same direction than those from a Dutch study [11], in which self-reported health problems pointed to a better health in rural areas, although this could not be confirmed by the information available on GP records.

Figure 3 shows the joint distribution of IS and PICH incidence across community-based studies with standardized rates (European population) or if data were available for calculation [12-34]. The IS incidence ranged from 57/100,000 in Menorca [29] to 255/100,000 in 
Correia et al.: Stroke Types in Rural and Urban Northern Portugal: Incidence and

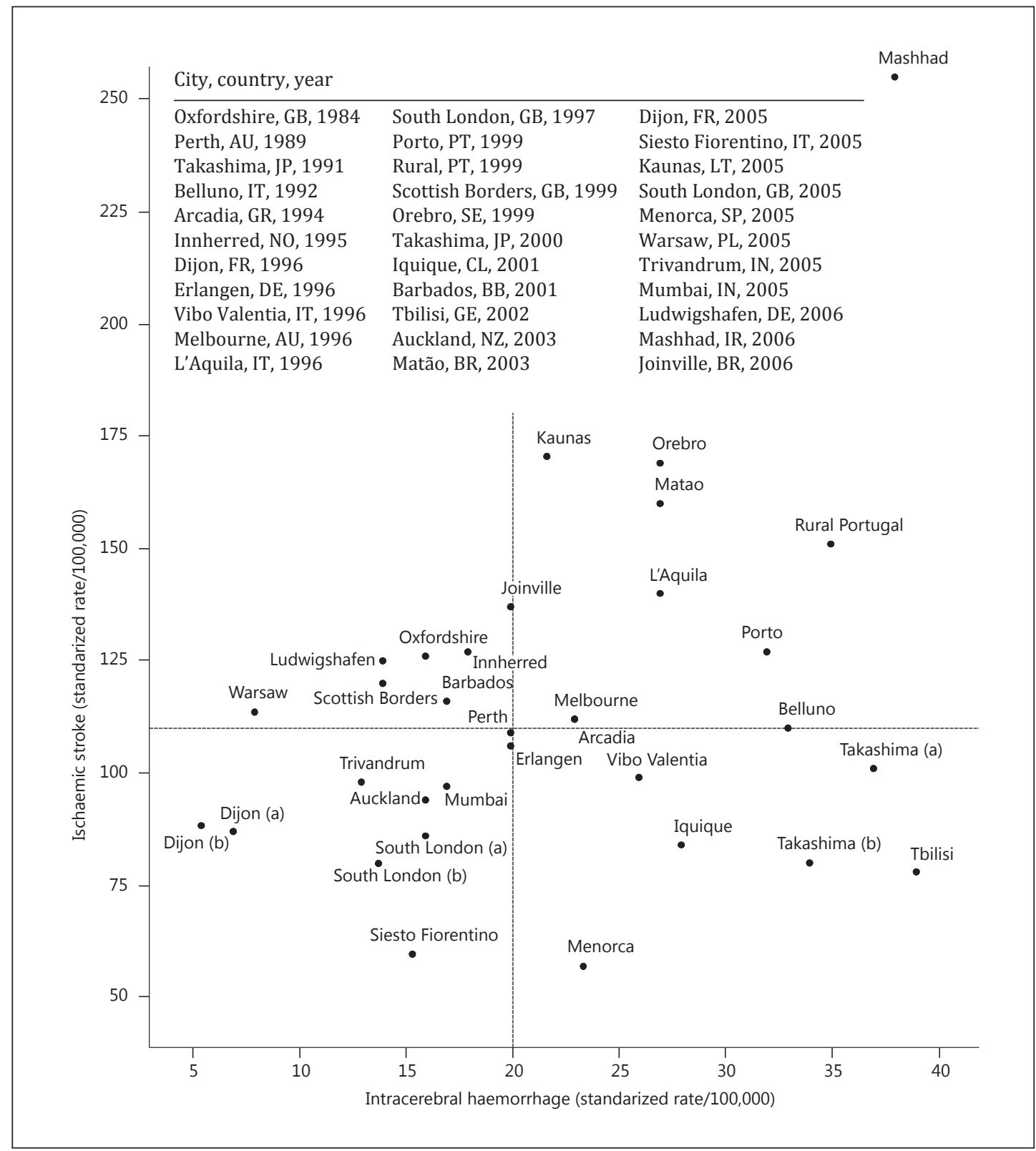

Fig. 3. Joint distribution of standardized IS and intracerebral haemorrhage incidence in community-based studies. The lines represent the median values.

Mashhad [33], and the incidence of PICH ranged from 6/100,000 in Dijon [29] to 39/100,000 in Tbilisi [26]. Both Portuguese urban and rural populations are in the upper-right quadrant, indicating a relatively high incidence of both IS and PICH, with the first being only higher in Mashhad, Kaunas, Orebro and Matão [23, 28, 29, 33] and the latter in Mashhad, Tbilisi and Takashima [14, 26, 33]. Apart from Japan, studies in Greece [16], Italy [15, 19, 21] and Georgia [26] also reported a relatively high incidence of PICH, probably linked to the high prevalence of hypertension and excess of salt in the Mediterranean diet, similar to the Japanese diet with a high consumption of salted fish [35]. The standardized incidence of SAH in this group of studies ranged from 1 to 16/100,000 (median =6/100,000), and the values in Portugal are 
close to the median. The comparison of the incidence of stroke types may be biased since the incidence of undetermined strokes could be as high as 59/100,000 (Trivandrum [30]), resulting from the low proportions of patients investigated with brain CT/MR scan and/or with a postmortem examination. Though we verified that there was no linear correlation between the year of the study and the standardized incidence of the different stroke types, the same could not be said in relation to the prevalence of VRF as a trend towards a lower incidence of PICH was found in repeated studies in Takashima [14], South London and Dijon $[18,29]$ (fig. 2). Nevertheless, in comparison with other studies, the prevalence of hypertension in patients from an urban area, representing a population-attributable risk for IS of $45.2 \%$ and for PICH of 73.6\% [36], is among the highest (only exceeded in Oxfordshire [12] and Iquique [24]) for IS, and is the highest among Portuguese patients with PICH [15, 27, 37]; the same was found for diabetes mellitus, though the proportion of active smokers was relatively low compared to other studies $[12,15]$. Besides traditional risk factors, environmental factors such as cold weather [38] and dietary habits may explain the relatively high variation shown in incidence rates.

There was no evidence of rural/urban differences in short- and long-term case fatality for the stroke types, though IS tended to be less fatal in patients from urban areas, whereas $\mathrm{PICH}$ and SAH were less fatal in patients from rural areas. The overall early case fatality after an IS $(11.3 \%)$ found in this study is among the lowest values reported in all studies (range $10-26 \%)[12,13,15-26,28,32,34]$; the values for PICH $(30.6 \%)$ and SAH $(30.4 \%)$ are also among the lowest within the respective ranges $(20-61 \%$ for PICH $[23,25]$ and $8-50 \%$ for SAH $[15,18,20])$. The cumulative risk of death at 7 years follows an identical pattern as the 28-day case fatality in rural/urban populations, and the values are close to those reported in Perth after a FELS and higher than in Oxfordshire after an IS and lower for haemorrhagic stroke for a 5-year follow-up [39, 40]. As in these studies, the proportional mortality from stroke in this study abruptly decreased after the acute phase. Neither stroke type nor residence was a predictor of long-term survival after the acute phase, but most risk factors were at the same time prognostic factors. Besides age $<65$ years, diabetes, atrial fibrillation, heart disease and smoking habits were predictors of poor survival, while hypercholesterolaemia was not. These results confirm recent findings [41, 42] and may justify why long-term survival is not associated with urban/rural environment. Since the stroke care chain is similar for patients from rural and urban areas, the older rural patients may have indeed a better survival than expected because risk/prognostic factors are less prevalent among them.

We have shown that the high incidence of stroke in rural compared to urban populations from northern Portugal is largely accounted for by the high incidence of cerebral infarcts, particularly in the rural elderly. The relatively better prognosis of IS and PICH in northern Portugal compared to other regions may result from the relatively high incidence of IS among the youngest age group living in the city as well as the relatively low prevalence of VRF in the eldest rural patients, pointing to different public health strategies. For better understanding the rural/urban differences in IS incidence, future analysis should be focused on the incidence of clinical subtypes of IS, aetiology and associated VRF.

\section{Acknowledgement}

This work was supported by a grant from the Merk, Sharp \& Dhome Foundation, Portugal and the Fundação para a Ciência e Tecnologia grant FCT/FEDER project POCI/ SAU-ESP/59885/2004. The Northern Region Health Authorities agreed and funded the investigator meetings. 


\section{Cerebrovascular Diseases}

\begin{tabular}{l|l}
\hline \multicolumn{2}{l}{ Cerebrovasc Dis Extra 2013;3:137-149 } \\
\hline DOI: $10.1159 / 000354851$ & $\begin{array}{l}\text { ( ) 2013 S. Karger AG, Basel } \\
\text { www.karger.com/cee }\end{array}$ \\
\hline
\end{tabular}

Correia et al.: Stroke Types in Rural and Urban Northern Portugal: Incidence and 7-Year Survival in a Community-Based Study

\section{Disclosure Statement}

The authors have no conflicts of interest with respect to this work.

\section{References}

$>1$ OECD: Health at a Glance 2011: OECD Indicators. OECD Publishing, 2011. http://www.oecd.org/health/ health-systems/healthataglance2011.htm.

2 DGS: Risco de Morrer em Portugal, 1999. Lisboa, Direcção-Geral da Saúde, 2001.

-3 Correia M, Silva MR, Matos I, Magalhães R, Lopes JC, Ferro JM, Silva MC: Prospective community-based study of stroke in Northern Portugal: incidence and case fatality in rural and urban populations. Stroke 2004;35: 2048-2053.

-4 Sudlow CL, Warlow CP: Comparing stroke incidence worldwide: what makes studies comparable? Stroke 1996;27:550-558.

-5 Sudlow CL, Warlow CP: Comparable studies of the incidence of stroke and its pathological types: results from an international collaboration. International Stroke Incidence Collaboration. Stroke 1997;28:491-499.

6 Keir SL, Wardlaw JM, Warlow CP: Stroke epidemiology studies have underestimated the frequency of intracerebral haemorrhage. A systematic review of imaging in epidemiological studies. J Neurol 2002;249:12261231.

7 Hatano S: Experience from a multicentre stroke register: a preliminary report. Bull World Health Organ 1976; 54:541-553.

8 Census 2001: Instituto Nacional de Estatística. http://www.ine.pt/xportal/xmain?xpid=INE\&xpgid=ine publicacoes\&PUBLICACOESpub_boui=5595518\&PUBLICACOEStema $=5414321 \&$ PUBLICACOESmodo $=2$

9 Waterhouse J: Cancer Incidence in Five Continents. Lyon, International Agency for Research on Cancer, 1982.

10 Moreira E, Correia M, Magalhães R, Silva MC: Stroke awareness in urban and rural populations from northern Portugal: knowledge and action are independent. Neuroepidemiology 2011;36:265-273.

11 Kroneman M, Verheij R, Tacken M, van der Zee J: Urban-rural health differences: primary care data and self reported data render different results. Health Place 2010;16:893-902.

12 Bamford J, Sandercock P, Dennis M, Burn J, Warlow C: A prospective study of acute cerebrovascular disease in the community: the Oxfordshire Community Stroke Project - 1981-86. 2. Incidence, case fatality rates and overall outcome at one year of cerebral infarction, primary intracerebral and subarachnoid haemorrhage. J Neurol Neurosurg Psychiatry 1990;53:16-22.

13 Anderson CS, Jamrozik KD, Burvill PW, Chakera TM, Johnson GA, Stewart-Wynne EG: Determining the incidence of different subtypes of stroke: results from the Perth Community Stroke Study, 1989-1990. Med J Aust 1993;158:85-89.

14 Kita Y, Turin TC, Ichikawa M, Sugihara H, Morita Y, Tomioka N, Rumana N, Okayama A, Nakamura Y, Abbott RD, Ueshima H: Trend of stroke incidence in a Japanese population: Takashima stroke registry, 1990-2001. Int J Stroke 2009;4:241-249.

15 Lauria G, Gentile M, Fassetta G, Casetta I, Agnoli F, Andreotta G, Barp C, Caneve G, Cavallaro A, Cielo R, et al: Incidence and prognosis of stroke in the Belluno province, Italy. First-year results of a community-based study. Stroke 1995;26:1787-1793.

16 Vemmos KN, Bots ML, Tsibouris PK, Zis VP, Grobbee DE, Stranjalis GS, Stamatelopoulos S: Stroke incidence and case fatality in southern Greece: the Arcadia stroke registry. Stroke 1999;30:363-370.

$\checkmark 17$ Ellekjaer H, Holmen J, Indredavik B, Terent A: Epidemiology of stroke in Innherred, Norway, 1994 to 1996. Incidence and 30-day case-fatality rate. Stroke 1997;28:2180-2184.

18 Wolfe CD, Giroud M, Kolominsky-Rabas P, Dundas R, Lemesle M, Heuschmann P, Rudd A: Variations in stroke incidence and survival in 3 areas of Europe. European Registries of Stroke (EROS) Collaboration. Stroke 2000; 31:2074-2079.

19 Di Carlo A, Inzitari D, Galati F, Baldereschi M, Giunta V, Grillo G, Furchi A, Manno V, Naso F, Vecchio A, Consoli D: A prospective community-based study of stroke in Southern Italy: the Vibo Valentia incidence of stroke study (VISS). Methodology, incidence and case fatality at 28 days, 3 and 12 months. Cerebrovasc Dis 2003;16: 410-417.

20 Thrift AG, Dewey HM, Macdonell RA, McNeil JJ, Donnan GA: Incidence of the major stroke subtypes: initial findings from the North East Melbourne stroke incidence study (NEMESIS). Stroke 2001;32:1732-1738.

21 Carolei A, Marini C, Di Napoli M, Di Gianfilippo G, Santalucia P, Baldassarre M, De Matteis G, di Orio F: High stroke incidence in the prospective community-based L'Aquila registry (1994-1998). First year's results. Stroke 1997;28:2500-2506.

22 Syme PD, Byrne AW, Chen R, Devenny R, Forbes JF: Community-based stroke incidence in a Scottish population: the Scottish Borders Stroke Study. Stroke 2005;36:1837-1843.

23 Appelros P, Nydevik I, Seiger A, Terent A: High incidence rates of stroke in Orebro, Sweden: further support for regional incidence differences within Scandinavia. Cerebrovasc Dis 2002;14:161-168. 
24 Lavados PM, Sacks C, Prina L, Escobar A, Tossi C, Araya F, Feuerhake W, Galvez M, Salinas R, Alvarez G: Incidence, 30-day case-fatality rate, and prognosis of stroke in Iquique, Chile: a 2-year community-based prospective study (PISCIS project). Lancet 2005;365:2206-2215.

-25 Corbin DO, Poddar V, Hennis A, Gaskin A, Rambarat C, Wilks R, Wolfe CD, Fraser HS: Incidence and case fatality rates of first-ever stroke in a black Caribbean population: the Barbados Register of Strokes. Stroke 2004;35: 1254-1258.

-26 Tsiskaridze A, Djibuti M, van Melle G, Lomidze G, Apridonidze S, Gauarashvili I, Piechowski-Jozwiak B, Shakarishvili R, Bogousslavsky J: Stroke incidence and 30-day case-fatality in a suburb of Tbilisi: results of the first prospective population-based study in Georgia. Stroke 2004;35:2523-2528.

27 Feigin V, Carter K, Hackett M, Barber PA, McNaughton H, Dyall L, Chen MH, Anderson C: Ethnic disparities in incidence of stroke subtypes: Auckland Regional Community Stroke Study, 2002-2003. Lancet Neurol 2006; 5:130-139.

28 Minelli C, Fen LF, Minelli DP: Stroke incidence, prognosis, 30-day, and 1-year case fatality rates in Matao, Brazil: a population-based prospective study. Stroke 2007;38:2906-2911.

29 Heuschmann PU, Di Carlo A, Bejot Y, Rastenyte D, Ryglewicz D, Sarti C, Torrent M, Wolfe CD: Incidence of stroke in Europe at the beginning of the 21st century. Stroke 2009;40:1557-1563.

-30 Sridharan SE, Unnikrishnan JP, Sukumaran S, Sylaja PN, Nayak SD, Sarma PS, Radhakrishnan K: Incidence, types, risk factors, and outcome of stroke in a developing country: the Trivandrum Stroke Registry. Stroke 2009;40:1212-1218.

-31 Dalal PM, Malik S, Bhattacharjee M, Trivedi ND, Vairale J, Bhat P, Deshmukh S, Khandelwal K, Mathur VD: Population-based stroke survey in Mumbai, India: incidence and 28-day case fatality. Neuroepidemiology 2008;31:254-261.

-32 Palm F, Urbanek C, Rose S, Buggle F, Bode B, Hennerici MG, Schmieder K, Inselmann G, Reiter R, Fleischer R, Piplack KO, Safer A, Becher H, Grau AJ: Stroke incidence and survival in Ludwigshafen am Rhein, Germany: the Ludwigshafen Stroke Study (LuSSt). Stroke 2010;41:1865-1870.

33 Azarpazhooh MR, Etemadi MM, Donnan GA, Mokhber N, Majdi MR, Ghayour-Mobarhan M, Ghandehary K, Farzadfard MT, Kiani R, Panahandeh M, Thrift AG: Excessive incidence of stroke in Iran: evidence from the Mashhad Stroke Incidence Study (MSIS), a population-based study of stroke in the Middle East. Stroke 2010; 41:e3-e10.

-34 Cabral NL, Goncalves AR, Longo AL, Moro CH, Costa G, Amaral CH, Fonseca LA, Eluf-Neto J: Incidence of stroke subtypes, prognosis and prevalence of risk factors in Joinville, Brazil: a 2 year community based study. J Neurol Neurosurg Psychiatry 2009;80:755-761.

-35 Montonen J, Jarvinen R, Reunanen A, Knekt P: Fish consumption and the incidence of cerebrovascular disease. Br J Nutr 2009;102:750-756.

-36 O’Donnell MJ, Xavier D, Liu L, Zhang H, Chin SL, Rao-Melacini P, Rangarajan S, Islam S, Pais P, McQueen MJ, Mondo C, Damasceno A, Lopez-Jaramillo P, Hankey GJ, Dans AL, Yusoff K, Truelsen T, Diener HC, Sacco RL, Ryglewicz D, Czlonkowska A, Weimar C, Wang X, Yusuf S: Risk factors for ischaemic and intracerebral haemorrhagic stroke in 22 countries (the INTERSTROKE study): a case-control study. Lancet 2010;376:112-123.

37 Hajat C, Dundas R, Stewart JA, Lawrence E, Rudd AG, Howard R, Wolfe CD: Cerebrovascular risk factors and stroke subtypes: differences between ethnic groups. Stroke 2001;32:37-42.

-38 Magalhaes R, Silva MC, Correia M, Bailey T: Are stroke occurrence and outcome related to weather parameters? Results from a population-based study in northern Portugal. Cerebrovasc Dis 2011;32:542-551.

-39 Hankey GJ, Jamrozik K, Broadhurst RJ, Forbes S, Burvill PW, Anderson CS, Stewart-Wynne EG: Five-year survival after first-ever stroke and related prognostic factors in the Perth Community Stroke Study. Stroke 2000;31:2080-2086.

40 Dennis MS, Burn JP, Sandercock PA, Bamford JM, Wade DT, Warlow CP: Long-term survival after first-ever stroke: the Oxfordshire Community Stroke Project. Stroke 1993;24:796-800.

-41 Weng WC, Huang WY, Su FC, Chien YY, Wu CL, Lee TH, Peng TI: Less favorable neurological recovery after acute stroke in patients with hypercholesterolemia. Clin Neurol Neurosurg 2013;115:1446-1450.

42 Kim J, Gall SL, Dewey HM, Macdonell RA, Sturm JW, Thrift AG: Baseline smoking status and the long-term risk of death or nonfatal vascular event in people with stroke: a 10-year survival analysis. Stroke 2012;43:31733178. 